\title{
A Re-Examination of the Unbiased Forward Rate Hypothesis in the Presence of Multiple Unknown Structural Breaks
}

\author{
Abdulnasser Hatemi-J \\ UAE University \\ E-mail: AHatemi@uaeu.ac.ae \\ Eduardo Roca \\ Department of Accounting, Finance and Economics, \\ Griffith University \\ Nathan, Queensland, Australia 4111 \\ Tel: +61-7-38757583, Fax: +61-7-3875 7760 \\ Email: E.Roca@griffith.edu.au \\ (Corresponding Author)
}

\begin{abstract}
We test the unbiased forward rate (UFR) hypothesis using new tests for cointegration developed by Hatemi-J (2008) that allows for multiple unknown structural breaks. We analyse the AUD, EUR, GBP and JPY (versus the USD) spot rates and forward rates relationship during the period January 7, 1999 to December 28, 2006. We find that the UFR does hold when the effects of the unknown structural breaks are taken into account. The parameters that we obtained were close to unity; hence, taking into account transactions cost and the existence of a risk premium, earning arbitrage profits may still not be possible. Thus, the markets for these currencies may still be considered as efficient.
\end{abstract}

Running title: A Re-Examination of the Unbiased Forward Rate Hypothesis JEL Classification: C32, F31

Keywords: Unbiased Forward Hypothesis, Foreign Exchange Market, Multiple Breaks 


\section{Introduction}

The unbiased forward rate (UFR) hypothesis states that the forward rate is an unbiased and efficient predictor of the future spot rates since it fully reflects all available information concerning agents' expectations of the future spot rate. This may be expressed as follows:

$$
s_{t+1}=f_{t}+u_{t+1}
$$

where $s_{t+1}$ is the spot rate at time $t+1, f_{t}$ is the forward rate at time $t$, and $u_{t+1}$ the error term which is a random component with an expected value of zero and serially uncorrelated with the information set available to agents at time $t$.

The UFR hypothesis is derived based on two assumptions that reflect market efficiency (Hakkio and Rush, 1989; Zacharatos and Sutcliffe, 2002):

(a) Agents are risk neutral, so that the risk premium is zero, which therefore ensures that through arbitrage this equality, is achieved.

$$
E\left(s_{t+1}\right)=f_{t}
$$

Here, $E\left(s_{t+1}\right)$ is the market's expectation of the spot rate at time $t+1$, which is based on the information set available at that time.

(b) Agents use all available information rationally, so that the expected returns to speculators are zero.

$$
s_{t+1}=E\left(s_{t+1}\right)+u_{t+1}
$$

Combining these two conditions therefore produces the unbiased forward hypothesis expressed in Equation 2:

$$
\begin{aligned}
s_{t+1} & =E\left(s_{t+1}\right)+u_{t+1} \\
& =f_{t}+u_{t+1}
\end{aligned}
$$

Given the assumptions behind the UFR, if it holds, then it is an indication that the foreign exchange market is efficient.

For purposes of testing the unbiased forward rate hypothesis, Equation 1 is re-formulated into the following equations: 


$$
\begin{aligned}
& s_{t+1}=a+b f_{t}+e_{t} \\
& \left(s_{t+1}-s_{t}\right)=a+b\left(f_{t}-s_{t}\right)+v_{t}
\end{aligned}
$$

If UFR is to hold in strong form, this requires that $a=0$ and $b=1$.

Before the development of the cointegration methodology, the second formulation was preferred in order to avoid the issue of non-stationarity. However, this has been discredited by Lin and Maddala (1992) by showing that simultaneous equation bias exists with this specification. This therefore left researchers with a dilemma. With the advent of cointegration, the focus of the testing has shifted to the first formulation.

The bulk of empirical evidence shows that this postulated relationship does not hold and hence, is labeled as a "paradox". Forward premiums have been found to be negatively, rather than positively related with spot rate changes (Froot and Thaler, 1990; Bekaert, 1996; Bekaert et. al., 1997). There are a number of studies, which have utilised the cointegration approach within a vector autoregression context following the Johansen procedure. Most researchers found cointegration between the two variables but the cointegration vector has not necessarily been (-1.0 and 1.0) (see, for instance, Villanueva, 2007; McMillan, 2005 and Jung et al, 1998).

Several economic explanations have been put forward for this "paradox" ranging from the presence of a risk premium (Taylor, 1995 and Froot and Frankel, 1989) to rational systematic errors, i.e. peso problems (Hodrick, 1987 and Engel, 1996). It has also been claimed that this paradox could be simply a statistical phenomenon arising from such problems as autocorrelation in the forward premium, as shown by Baillie and Bollerslev (2000) or simultaneous equation bias, as demonstrated in Barnhart, et. al. (1999). It is not clear from these studies whether the condition of the error term being a white noise has been met since cointegration requires that the error term be stationary.

In this paper, we examine the unbiased forward hypothesis with the use of new cointegration tests suggested by Hatemi-J (2008), which can be used for testing cointegration in the presence of two potential structural breaks, which are unknown and determined by the data. We cover the period from January 7, 1999 to December 28, 2006 using weekly Australian dollar (AUD), Euro (EUR), Japanese yen (JPY), and British pound (GBP) (versus the US dollar or USD) spot rates and 3-month forward rates. We obtained the data from Datastream. 
Our study extends the literature on the spot-forward relationship in terms of the application of new approaches to the issue. It sheds further light on the claim by a number of previous researches that the paradox is simply a statistical phenomenon. This group of research used other approaches, and as stated earlier, it is possible that their results could have been affected by statistical inference bias due to the existence of structural breaks in the data. ${ }^{1}$

The importance of the relationship between the spot rate and forward rate in the foreign exchange market is well-recognised as evidenced by the continuing studies conducted on this issue $^{2}$. In addition to its implication on market efficiency, theoretically, this relationship is an important input into foreign exchange models. It is also highly important to policymakers in terms of setting appropriate foreign exchange policies and to investors in the foreign exchange markets in terms of their search for profitable opportunities. Another importance of knowing this relationship is in terms of hedging as forward contracts are used to hedge spot investments.

The remaining parts of the paper are organised in this manner. Section 2 discusses the methodology while Section 3 presents the empirical results. Section 4 provides a conclusion to the study.

\section{Methodology}

As mentioned earlier, we utilise cointegration tests developed by Hatemi-J (2008) that allow for multiple structural breaks. In order to apply these tests, first, we reformulate equation (5), as follows, in order to take into account the impact of two structural breaks:

$$
S_{t}=\alpha_{0}+\alpha_{1} D_{1 t}+\alpha_{2} D_{2 t}+\beta_{0} F_{t}+\beta_{1} D_{1 t} F_{t}+\beta_{2} D_{2 t} F_{t}+u_{t}
$$

where $D_{1 t}$ and $D_{2 t}$ are binary indicator variables that are defined in the following form:

$D_{1 t}=\left\{\begin{array}{lll}0 & \text { if } & t \leq\left[n \tau_{1}\right] \\ 1 & \text { if } & t>\left[n \tau_{1}\right]\end{array}\right.$

\footnotetext{
${ }^{1}$ It should be pointed out that Choi and Zivot (2007) provide evidence for multiple structural changes in the mean of the G7 countries' forward rates.

${ }^{2}$ In addition to the literature cited earlier, see also Sercu, et al (2008); Diamandis, et al (2008); Chen (2007);

Sekioua (2006), Wang (2005); Apergis and Eleftheriou (1997) as well as Ahmed and Ansari (1997).
} 
and

$D_{2 t}=\left\{\begin{array}{lll}0 & \text { if } & t \leq\left[n \tau_{2}\right] \\ 1 & \text { if } & t>\left[n \tau_{2}\right]\end{array}\right.$

The unknown parameters $\tau_{1} \in(0,1)$ and $\tau_{2} \in(0,1)$ measure the relative timing of the regime shift points. The bracket denotes the integer part since $n$ is the number of observations.

We utilise three tests for cointegration in the presence of two unknown structural breaks, which are denoted by $A D F, Z_{\alpha}$ and $Z_{t}$ respectively. We calculate the $A D F$ test based on the $t$ test for the slope of $\hat{a}_{t-1}$ in a regression of $\Delta \hat{a}_{t}$ on $\hat{u}_{t-1}, \Delta \hat{a}_{t-1}, \cdots, \Delta \hat{a}_{t-k}$, where $\hat{u}_{t}$ is the residuals from equation (7). We determine the lag order $k$ by minimizing an information criterion suggested by Hatemi-J $(2003,2008 \mathrm{~b}) .{ }^{3}$ The $Z_{\alpha}$ and $Z_{t}$ test statistics are estimated based on the following bias-corrected first-order serial correlation coefficient: ${ }^{4}$

$$
\hat{\rho}^{*}=\frac{\sum_{t=1}^{n-1}\left(a_{t} a_{t+1}-\sum_{j=1}^{B} w(j / B) \gamma(j)\right)}{\sum_{t=1}^{n-1} \hat{u}_{t}^{2}},
$$

where $w(\cdot)$ is a function that determines the kernel weights fulfilling the standard conditions for spectral density estimators and $B$ represents the bandwidth. The autocovariance function is calculated as

$$
\hat{\gamma}(j)=\frac{1}{n} \sum_{t=j+1}^{T}\left(\hat{u}_{t-j}-\hat{\rho} \hat{u}_{t-j-1}\right)\left(\hat{u}_{t}-\hat{\rho} \hat{u}_{t-1}\right),
$$

where $\hat{\rho}$ is the ordinary least squares estimate of the effect (without intercept) of $\hat{u}_{t-1}$ on $\hat{u}_{t}$. The $Z_{\alpha}$ and $Z_{t}$ test statistics are then obtained as

$$
Z_{\alpha}=n\left(\hat{\rho}^{*}-1\right)
$$

and

$$
Z_{t}=\frac{\left(\hat{\rho}^{*}-1\right)}{\left(\hat{\gamma}(0)+2 \sum_{j=1}^{B} w(j / B) \hat{\gamma}(j)\right) / \sum_{1}^{n-1} \hat{u}_{t}^{2}}
$$

\footnotetext{
${ }^{3}$ According to the simulation experiments conducted by Hatemi-J (2008b) this information criterion performs well in situations where unit roots or ARCH effects prevail.

${ }^{4}$ The $Z_{\alpha}$ and $Z_{t}$ tests were originally introduced by Philips (1987). It should be mentioned that Gabriel et al (2002) suggested applying a Markov switching approach to test for cointegration in the presence of breaks.
} 
where $\hat{\gamma}(0)+2 \sum_{j=1}^{B} w(j / B) \hat{\gamma}(j)$ is the long-run variance measure of the residuals of a regression of $a_{t}$ on $a_{t-1} \cdot{ }^{5}$ The appropriate test statistics are the minimum values of these three tests across all possible values for $\tau_{1}$ and $\tau_{2}$, with $\tau_{1} \in T_{1}=(0.15,0.70)$ and $\tau_{2} \in T_{2}=\left(0.15+\tau_{1}, 0.85\right)$. We choose the minimum value of each test because the smallest value provides the empirical evidence in favor of the cointegration relationship. The minimum values of these test statistics are mathematically defined as

$$
\begin{aligned}
& A D F^{*}=\inf _{\left(\tau_{1}, \tau_{2}\right) \in T} A D F\left(\tau_{1}, \tau_{2}\right), \\
& Z_{t}^{*}=\inf _{\left(\tau_{1}, \tau_{2}\right) \in T} Z_{t}\left(\tau_{1}, \tau_{2}\right), \\
& Z_{\alpha}^{*}=\inf _{\left(\tau_{1}, \tau_{2}\right) \in T} Z_{\alpha}\left(\tau_{1}, \tau_{2}\right),
\end{aligned}
$$

where $T=(0.15 n, 0.85 n)$. We truncate the data by $15 \%$ on each side, following Gregory and Hansen (1996), who developed tests for cointegration for one unknown structural break. ${ }^{6}$ Using the same reasoning, we also allow the distance between the two regime shifts to be at least $15 \%$. The calculations are conducted by utilizing a statistical software component in Gauss produced by Hatemi-J (2009). This statistical software is available on line.

\section{Empirical Results}

Prior to testing for cointegration, we conducted unit roots tests. The results, not reported but available on request, showed that each variable is integrated of the first order even in the presence of two breaks in their deterministic components. The graphical illustration of these variables depicted in Figure 1 also confirms this conclusion. This implies that we have to pay attention to the integration properties of the data in order to avoid spurious and false inference.

\section{[INSERT FIGURE 1 HERE]}

\footnotetext{
${ }^{5}$ The long-run variance is calculated by using an automatic bandwidth estimator and a prewhitened quadratic spectral kernel with a first-order autoregression for the prewhitening. For more details on this, see Andrews (1991) and Andrews and Monahan (1992).

${ }^{6}$ See Gregory et al (1996) for the power properties of tests for structural breaks in cointegrated relationships. See also Cook (2006) for the power tests for cointegration that are base on a single equation. For other multiple structural breaks procedures we refer the interested reader to Bai (1997) as well as Bai and Perron $(1998,2003)$.
} 
The results of the tests for cointegration in the presence of two unknown structural breaks are presented in Table 1. As can be seen from these results, the null hypothesis of no cointegration is strongly rejected by all three tests for each currency. The timing of each break as determined by the method used in this study is shown as follows:

AUD: first break, September 2001; second break, October 2003.

JPY: first break, September 2001; second break, July 2003.

GBP: first break, April 2001; second break, June 2004.

EUR: first break, February 2001; second break, November 2003.

[INSERT TABLE 1 HERE]

The 2001 breaks are a result of the September 11 attack on the US while the 2003 ones, could be due to the effect of the Iraqi invasion which had significantly disrupted oil supply resulting in an abrupt change in oil prices which then affected exchange rates.

[INSERT TABLE 2 HERE]

As can be seen in Table 2, the slope value for the pre-break period is very close to unity for each exchange rate (see the estimated value for $\beta_{0}$ ) and it is strongly significant in each case. There are two significant breaks in the slope for the AUD (see the estimated values for $\beta_{1}$ and $\beta_{2}$ ). First, there is an increase in the parameter value and then a decrease in the parameter value. Despite being statistically significant, these changes are marginal. The first change is 0.015 and the second change is -0.054 . The same story is true regarding the JPY with the difference that both changes are positive. The first change is 0.028 and the second is 0.045 in the JPY. In the case of the GBP, there is only one significant change in the slope in the second period, which is equal to -0.02 . Both changes in the slope parameter are nonsignificant in the case of EUR. The risk premium is statistically significant in all cases except EUR (see the estimated values for $\alpha_{0}$ ). There are two significant changes in the case of the AUD and the JPY (see the estimated values for $\alpha_{1}$ and $\alpha_{2}$ ). In the case of the GBP, there is only one significant change in the premium, which happens in the second break period. No significant changes in the premium were found in the case of EUR. Based on this estimates 
we can conclude that the unbiased forward rate hypothesis holds most strongly in the case of the EUR.

\section{Conclusion}

The unbiased forward rate hypothesis stipulates that the forward rate is an unbiased predictor of future spot rates. Empirically, if this is to hold within a regression framework, there must be cointegration within the variables with point-for-point response. This paper is the first attempt to investigate these issues in the presence of two unknown structural breaks by applying a new test method recently developed in the literature. The timing of each break is selected by the method. In some cases the selected structural breaks coincide with the September 11 terrorist attack on the US and the 2003 Iraqi invasion.

Our results show that the UFR does hold and the parameters that we derived are close to unity. There are significant changes in the parameters for all exchange rates except for the EUR. However, the changes in the parameters are marginal. These results indicate that the market for these currencies are still efficient as these values may not allow the existence of arbitrage profits after taking into account transaction costs and risk premium. 


\section{References}

Ahmed, S. and M.I. Ansari (1997). Modelling the Efficiency of the Canadian Foreign Exchange Market: A Bivariate Transfer Function Analysis. Applied Economics, 1997, 29, 63-70.

Andrews, D.W.K (1991). Heteroscedasticity and Autocorrelation Consistent Covariance Matrix Estimation, Econometrica 59, 817-858.

Andrews, D.W.K and J.C. Monahan (1992). An Improved Heteroscedasticity and Autocorrelation Consistent Covariance Matrix Estimator, Econometrica 60, 953-966.

Apergis, N. and S. Eleftheriou (1997). The Efficient Hypothesis and Deregulation: The Greek Case, Applied Economics, 29, 111-117.

Bai J. (1997) Estimation of a Change Point in Multiple Regressions, Review of Economics and Statistics, 79, 551-563.

Bai J. and P. Perron (1998). Testing for and Estimation of Multiple Structural Changes, Econometrica, 66, 47-79.

Bai J. and P. Perron (2003) Computation and Analysis of Multiple Structural Changes, Journal of Applied Econometrics, 18, 1-22.

Baillie, R.T. and T. Bollerslev (2000). "The Forward Premium Anomaly Is Not As Bad As You Think", Journal of International Money and Finance, 19, 471-488.

Barnhart, S.W.; R. McNown and R. Wallace (1999). "Noninformative Tests of the Unbiased Forward Exchange Rate", Journal of Financial and Quantitative Analysis, 34, 2.

Bekaert, G. (1996). "The Time Variation of Risk and Return in Foreign Exchange Markets: A General Equilibrium Approach”, Review of Financial Studies, 9, 427-470.

Bekaert, G.; R.J. Hodrick and D.A. Marshall (1997). "The Implications of First Order Risk Aversion for Asset Market Risk Premiums", Journal of Monetary Economics, 40, 3-39.

Chen, S. (2007), Testing the Hypothesis of Market Efficiency in the Taiwan-US forward Exchange Market since 1990, Applied Economics, 1-12, iFirst.

Choi, K and E. Zivot (2008). Long memory and structural changes in the forward discount: An empirical investigation, Journal of International Money and Finance, 26(3), 342363.

Cook, S. (2006). The Power of Single Equation Tests for Cointegration, Applied Economics Letters, 13, 265-267.

Davison A.C. and D.V. Hinkley (1999). Bootstrap Methods and Their Application, Cambridge University Press. 
Diamandis, P.; D. Georgoutsos and G. Kouretas (2008). Testing the Forward Rate Unbiasedness Hypothesis During the 1920s, Journal of International Financial Markets, Institutions and Money, 18, 358-373.

Efron, B. (1979). "Bootstrap Methods: Another Look at the Jackknife". Annals of Statistics, 7, 1-26.

Engel, C. (1996). “The Forward Discount Anomaly and the Risk Premium: A Survey of Recent Evidence", Journal of Empirical Finance, 3, 123-192.

Froot, K.A. and J.A. Frankel (1989). "Forward Discount Bias: Is It an Exchange Risk Premium?", Quarterly Journal of Economics, 104, 139-160.

Froot, K.A. and R.H. Thaler (1990). “Anomalies: Forward Exchange”, Journal of Economic Perspectives, 4, 179-192.

Gabriel, V. J.; Z. Psaradakis and M. Sola, (2002). A Simple Method of Testing for Cointegration Subject to Multiple Regime Change, Economics Letters, 76, 213-221.

Gregory, A.W. and B. E. Hansen (1996). Residual-based Tests for Cointegration in Models with Regime Shifts, Journal of Econometrics, 70, 99-126.

Gregory, A.W.; J.M. Nason and D. Watt (1996). Testing for Structural Breaks in Cointegrated Relationships, Journal of Econometrics , 71(1-2), 321-341.

Hakkio, C.S. and M. Rush (1989). "Market Efficiency and Cointegration: An Application to the Sterling and Deutschemark Exchange Markets", Journal of International Money and Finance, 8, pp. 75-88.

Hatemi-J, A (2003). A New Method to Choose Optimal Lag Order in Stable and Unstable VAR Models, Applied Economics Letters, 10(3), 135-137.

Hatemi-J, A (2008b). Forecasting Properties of a New Method to Choose Optimal Lag Order in Stable and Unstable VAR Models, Applied Economics Letters, 15(4), 239-243.

Hatemi-J, A. (2008). Tests for Cointegration with Two Unknown Regime shifts. Empirical Economics, 35(3), 497-505.

Hatemi-J A. (2009) CItest2b: GAUSS module to implement tests for cointegration with two unknown structural breaks," Statistical Software Components, nr. G00006, Boston College Department of Economics.

Hodrick, R.J. (1987). The Empirical Evidence on the Efficiency of Forward and Future Foreign Exchange Markets. Switzerland: Harwood Academic Publishers.

Jung, C.; K. Doroodian and R. Albarano (1998). The Unbiased Forward Rate Hypothesis: A Re-Examination, Applied Financial Economics, 1998, 8, 567-575. 
McMillan, D. (2005). Cointegrating Behavior Between Spot and Forward Exchange Rates, Applied Financial Economics, 2005, 15, 1135-1144.

Newey W. K. and D.K. West (1987). A Simple, Positive Semi-definite, Heteroskedasticity and Autocorrelation Consistent Covariance Matrix. Econometrica 55, 703-708.

Phillips, P.C.B. (1987). Time Series Regression with a Unit Root. Econometrica 55, 277-301.

Sekioua, S. (2006). Nonlinear Adjustment in the Forward Premium: Evidence from a Threhold Unit Root Test, International Review of Economics and Finance, 15,164-183.

Sercu, P., M. Vandebroek and X. Wu (2008). Is the Forward Bias Economically Small? Evidence from European Rates, Journal of International Money and Finance, 27 (2008) 1284-1302.

Taylor, M.P. (1995). “The Economics of Exchange Rates”, Journal of Economic Literature, Letters, 6, 703-705.

Villanueva, O.M. (2007). Spot-Forward Cointegration, Structural Breaks and FX Market Unbiasedness, Journal of International Financial Markets, Institutions and Money, 17, 58-78.

Wang, P. (2005), A Re-Examination of the Predicting Power of Forward Premia, Applied Financial Economics,15, 1219-1225.

Zacharatos, N. and C. Sutcliffe (2002). "Is the Forward Rate for the Greek Drachma Unbiased? A VECM Analysis with both Overlapping and Non-Overlapping Data”. Journal of Financial Management and Analysis. 15, pp. 27-37.

Zivot, E. and D.W.K Andrews (1992). Further Evidence on the Great Crash, the Oil Shock, and the Unit-Root Hypothesis, Journal of Business and Economic Statistics, 10, 251-270. 
Table 1. The Results of Tests for Cointegration between Spot and Forward Rates

\begin{tabular}{|c|c|c|c|c|c|}
\hline Currency & Test Statistic & $\begin{array}{l}\text { Estimated } \\
\text { Test Value }\end{array}$ & $\begin{array}{c}1 \% \text { Critical } \\
\text { Value }\end{array}$ & $\begin{array}{c}\text { 5\% Critical } \\
\text { Value }\end{array}$ & $\begin{array}{c}10 \% \text { Critical } \\
\text { Value }\end{array}$ \\
\hline \multirow{3}{*}{$A U D$} & $A D F^{*}$ & -18.179 & -6.503 & -6.015 & -5.653 \\
\hline & $Z^{*}{ }_{t}$ & -18.207 & -6.503 & -6.015 & -5.653 \\
\hline & $Z_{\alpha}^{*}$ & -368.777 & -90.794 & -76.003 & -52.232 \\
\hline \multirow{3}{*}{$J P Y$} & $A D F^{*}$ & -9.956 & -6.503 & -6.015 & -5.653 \\
\hline & $Z^{*}{ }_{t}$ & -14.094 & -6.503 & -6.015 & -5.653 \\
\hline & $Z_{\alpha}^{*}$ & -246.529 & -90.794 & -76.003 & -52.232 \\
\hline \multirow{3}{*}{ GBP } & $A D F^{*}$ & -17.724 & -6.503 & -6.015 & -5.653 \\
\hline & $Z^{*}{ }_{t}$ & -17.837 & -6.503 & -6.015 & -5.653 \\
\hline & $Z^{*}{ }_{a}$ & -359.679 & -90.794 & -76.003 & -52.232 \\
\hline \multirow{3}{*}{$E U R$} & $A D F^{*}$ & -17.130 & -6.503 & -6.015 & -5.653 \\
\hline & $Z^{*}{ }_{t}$ & -17.150 & -6.503 & -6.015 & -5.653 \\
\hline & $Z^{*}{ }_{\alpha}$ & -344.878 & -90.794 & -76.003 & -52.232 \\
\hline
\end{tabular}

Notes: The critical values are collected from Hatemi-J (2008). 
Table 2. The Estimated Values of the Parameters

\begin{tabular}{|c|c|c|c|c|c|c|}
\hline Currency & $\alpha_{0}$ & $\alpha_{1}$ & $\alpha_{2}$ & $\beta_{0}$ & $\beta_{1}$ & $\beta_{2}$ \\
\hline \multirow{2}{*}{ AUD } & 0.020 & -0.040 & 0.079 & 0.988 & 0.015 & -0.054 \\
& $(1.603)$ & $(-2.468)$ & $(3.987)$ & $(12.434)$ & $(1.627)$ & $(-4.298)$ \\
\hline \multirow{2}{*}{ JPY } & 3.357 & -4.245 & -4.492 & 0.983 & 0.028 & 0.045 \\
& $(3.982)$ & $(-2.301)$ & $(-2.367)$ & $(6.035)$ & $(3.228)$ & $(4.420)$ \\
\hline \multirow{2}{*}{ GBP } & -0.007 & -0.002 & 0.014 & 1.011 & -0.003 & -0.020 \\
& $(-1.993)$ & $(-0.378)$ & $(2.557)$ & $(10.546)$ & $(-0.453)$ & $(-2.592)$ \\
\hline \multirow{2}{*}{ EUR } & 0.006 & -0.007 & 0.013 & 0.999 & -0.002 & -0.010 \\
& $(1.834)$ & $(-1.271)$ & $(1.698)$ & $(14.578)$ & $(-0.727)$ & $(-1.206)$ \\
\hline
\end{tabular}

Notes: The t-values are presented in the parentheses. The Newey-West heteroskedasticity and autocorrelation consistent standard errors are used. 
Figure 1: Forward and Spot rates for Australian dollar (AUD), Japanese yen (JPY), British pound (GBP) and Euro.

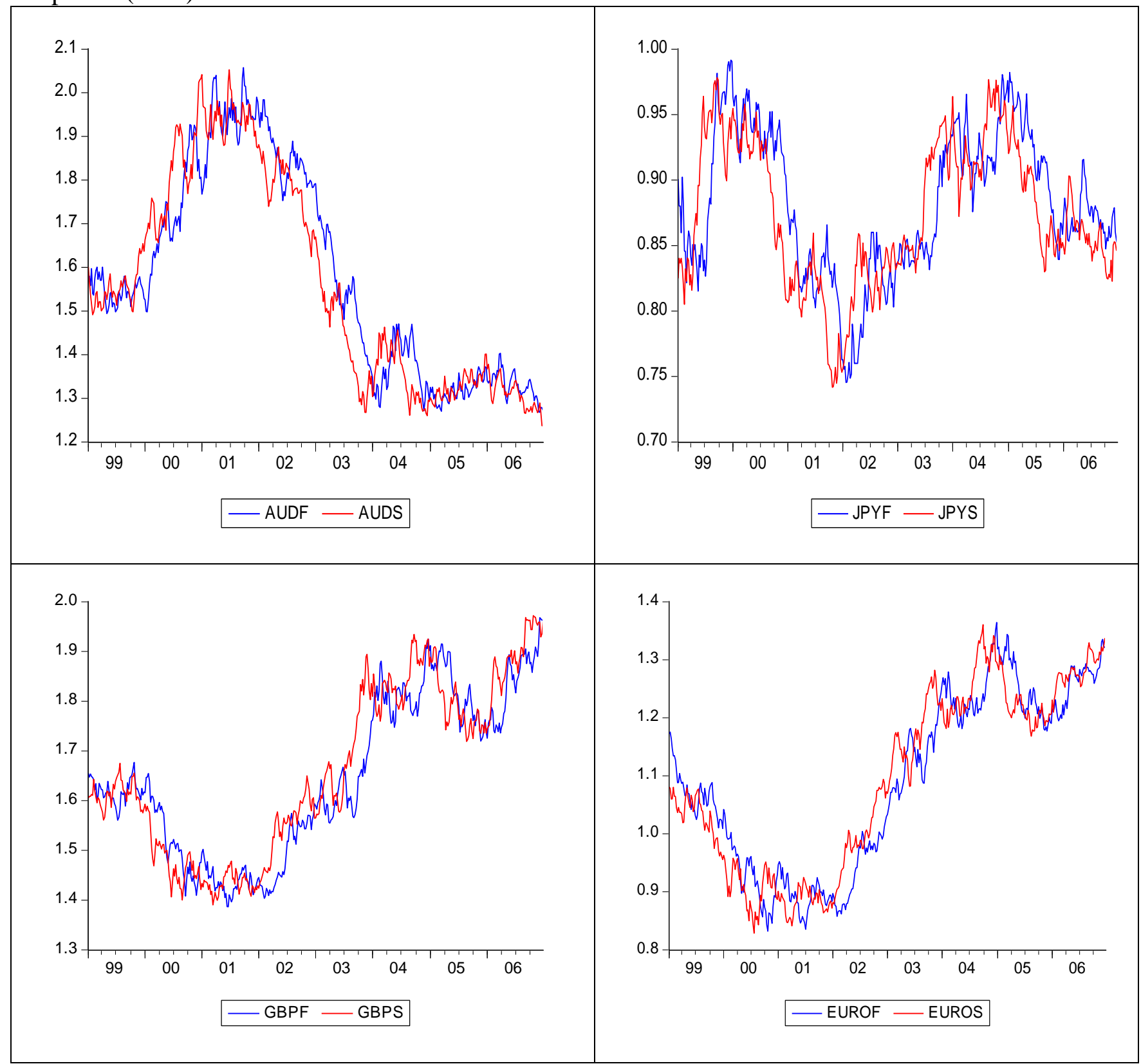

Note that $\mathrm{F}$ after each currency indicates forward rate and $\mathrm{S}$ indicates the spot rate. 